\title{
PROCEEDINGS OF THE DUTCH SOCIETY FOR CLINICAL PHARMACOLOGY AND BIOPHARMACY
}

\section{October 1999}

\author{
Selection of radionuclides for radiation \\ synovectomy with yttrium $\left({ }^{90} \mathrm{Y}\right)$, erbium \\ $\left({ }^{169} \mathrm{Er}\right)$ and samarium $\left({ }^{153} \mathrm{Sm}\right)$ : the concept of \\ a therapeutic window
}

M. W. KONIJNENBERG, G. J. ENSING \& H. H. VAN ROOIJ Mallinckrodt Medical B.V., P.O. Box 3, 1755 ZG Petten, The Netherlands

Radiation synovectomy is a palliative therapy for painful rheumatoid joints. A radioactive liquid with a $\beta$-emitting radionuclide is directly injected into the joint capsule. Synovectomy agents must be capable of delivering a high enough radiation dose to the phagocytic layer of the synovium around the joint capsule, which is causing the pain. The dose to the cartilage, the bone surface and the bone marrow, however, may not exceed any safety level of either deterministic or stochastic nature. This local dosimetry in the joint can be calculated with a Monte Carlo model [1]. Furthermore, the leakage of radioactive liquid from the joint into the rest of the body must be minimal, or at least after several half-times of decay of the radionuclide.

Monte Carlo dosimetry with the EGS4 code was performed for three radionuclides ${ }^{90} \mathrm{Y},{ }^{169} \mathrm{Er}$ and ${ }^{153} \mathrm{Sm}$. The results were analysed with dose-effect curves for efficacy in the synovial lining and unwanted side-effects in the cartilage and the bone, according to the standard report on deterministic effects from radiation [2]. A therapeutic window was defined between the activity that produces an efficacious dose in the synovium and the activity that can possibly damage the cartilage (Table 1).

It is recommended that theoretical radiation dosimetry studies should form an important part of the registration dossier for radio-pharmaceuticals intended for therapeutic use.

Table 1 Therapeutic window for locally injected radionuclides in radiation synovectomy.

\begin{tabular}{lccrrrrr}
\hline Therapentic window & \multicolumn{2}{c}{${ }^{90}$ Yactivity } & \multicolumn{2}{c}{${ }^{153}$ Sm activity } & \multicolumn{2}{c}{${ }^{169}$ Er activity } \\
\hline & $M B q$ & $m C i$ & $M B q$ & $m C i$ & $M B q$ & $m C i$ \\
$95 \%$ effect in synovium & 115 & 3.11 & 225 & 6.08 & 17 & 0.46 \\
$5 \%$ damage in cartilage & 205 & 5.54 & 1655 & 44.7 & 1120 & 30.3 \\
\hline
\end{tabular}

2 ICRP Publication 41. Nonstochastic effects of ionizing radiation, ed. Sowby FB. Oxford: Pergamon Press, 1984.

\section{Reducing anticholinergic antidepressant use in the elderly: a randomized trial of group $v s$ individual 'academic detailing'}

\footnotetext{
M. E. C. VAN EIJK ${ }^{1,2}$, J. AVORN ${ }^{3}$, A. J. PORSIUS ${ }^{1} \&$ A. DE BOER $^{1}$

${ }^{1}$ Department of Pharmacoepidemiology and Pharmacotherapy, Utrecht Institute of Pharmaceutical Sciences, Utrecht, ${ }^{2}$ Health Insurance Company 'OZ-zorgverzekeringen', Breda, The Netherlands and ${ }^{3}$ Division of Pharmacoepidemiology, Department of Medicine, Brigham and Women's Hospital, Harvard Medical School, Boston, USA
}

Dissemination of medical knowledge and implementation of knowledge need to be better understood. Academic detailing, consisting of repeated personal visits to care providers, feedback of past performance and clear practice-relevant recommendations, can effectively change prescribing, but it is very resource demanding [1]. This research compares the effect of an educational intervention through individual outreach visits and through a group (peer review group of general practitioners and pharmacists) approach, using academic detailing.

We conducted a randomized controlled trial to measure the effect of two educational programs on prescribing (individual intervention arm and group intervention arm vs control arm) to reduce anticholinergic antidepressant 
(AAD) prescribing for the elderly. We included all General Practitioners (GPs) and pharmacists (approximately 230) in the southwest Netherlands health district and used a database covering all prescriptions to persons insured by the national health insurance system in this area (approximately 240,000).

In the individual arm 43 of 70 GPs were visited; in the group arm 5 of 7 groups (41 of 52 GPs) agreed to join the program. Using an intention to treat analyses compared with the control group there was a reduction in the incidence of AAD in elderly of $26 \% \quad(95 \%$ confidence interval $-4 \%, 48 \%)$ in the individual arm and of $45 \%(8 \%$,
$67 \%)$ in the group arm. The use of non-AAD in the elderly increased by $40 \%(6 \%, 83 \%)$ in the individual arm and by $29 \%(-7 \%, 79 \%)$ in the group arm. There were no statistically significant differences between the two intervention arms.

Both the individual and the group approach decreased the incidence of AAD and increased the incidence of nonAAD use in the elderly. These approaches are practical means of improving the clinical appropriateness of medication use on a large scale among primary care physicians.

1 Soumerai SB, Avorn J. JAMA 1990; 263: 549.

\section{Estimation of prevalence of cholesterol lowering drug use in the general Dutch population}

\author{
A. K. TEEUWISSE ${ }^{1}$, W. M. M. VERSCHUREN ${ }^{2}$, \\ A. J. PORSIUS ${ }^{1} \&$ A. DE BOER ${ }^{1}$ \\ ${ }^{1}$ Utrecht Institute of Pharmaceutical Sciences (UIPS), Depart- \\ ment of Pharmacoepidemiology and Pharmacotherapy, Utrecht \\ University, Utrecht and ${ }^{2}$ Department of Chronic Diseases and \\ Environmental Epidemiology, National Institute of Public Health \\ and Environmental Protection, Bilthoven, The Netherlands
}

Our aim was to estimate the prevalence of cholesterol lowering drug use in the general Dutch population.

Data were obtained from the PHARMO record linkage system, a database comprising drug dispensing records from community pharmacies and linked hospital discharge records of a defined population of 300,000 residents of six mediumsized cities in the Netherlands [1]. Prescriptions of cholesterol lowering drugs as selected from ATC-codes B04 and C10 (statins, bile acid sequestrants, fibrates and nicotinic acid derivatives), with the exception of nicotinylalcohol $25 \mathrm{mg}$, were used. Prevalence was estimated on the third Wednesday of October, between 1991 and 1996. This day was chosen to rule out influence of vacation or weekend on drug dispensing. Prevalences were weighted for the age distribution of the general Dutch population.

Between 1991 and 1996 the prevalence of cholesterol lowering drug use increased by $230 \%$ in men $(0.60 \%$ in 1991 to $1.98 \%$ in 1996$)$ and by $217 \%$ in women $(0.52 \%$ to 1.65\%). The largest increase was observed between 1995 and 1996. Prevalence varied between age categories. Results in 1996 are shown in Table 1. In both men and women, prevalence is lowest in age category ' $<20$ years'. Prevalence increases with age and highest prevalence is observed in age category '60-69 years'. Subsequently, prevalence decreases in the elderly. The same pattern was observed in previous years.

Statins, in particular simvastatin, were the most frequently used cholesterol lowering drugs. In $199184 \%$ of all patients on cholesterol lowering medication used a statin. This percentage increased to $90 \%$ in 1996.

Cholesterol lowering drug treatment increased substantially during the period 1991-1996. Prevalence is lower in women than in men, but showed a similar age pattern.

\begin{tabular}{lcccccccc}
\hline & & \multicolumn{7}{c}{ Age (years) } \\
& $<20$ & $20-29$ & $30-39$ & $40-49$ & $50-59$ & $60-69$ & $70-79$ & $>79$ \\
\hline Men & 0.01 & 0.12 & 0.36 & 1.98 & 5.70 & 7.88 & 4.96 & 1.40 \\
Women & 0.01 & 0.08 & 0.24 & 0.76 & 3.52 & 7.00 & 5.88 & 1.35 \\
Total & 0.01 & 0.10 & 0.30 & 1.38 & 4.63 & 7.42 & 5.50 & 1.37 \\
\hline
\end{tabular}

Table 1 Prevalence of cholesterol lowering drug use in 1996 across age categories, data presented as percentages.

1 Herings RMC. Dissertation. Utrecht: Utrecht University, 1993. 


\section{Rectal administration of carbamazepine}

\section{E. H. WILTINK}

Department of Clinical Pharmacy, St Antonius Ziekenhuis, Koekoekslaan 1, 3435 CM Nieuwegein, The Netherlands

Carbamazepine is primarily indicated for the treatment of epilepsy. To achieve optimal seizure control and avoid toxicity, maintenance of therapeutic serum concentration is important. If the patient is unable to take oral medication an alternative route of administration is necessary. No parenteral formulation is available and the only other possibility is rectal administration. The literature about the rectal use of carbamazepine is limited. In man it concerns case reports or small studies in healthy volunteers and patients. One larger study with suppositories was done in 29 children between six and 14 years of age [1]. We have investigated the clinical use of carbamazepine suppositories in six consecutive patients (three males and three females, age 18 to 87 years) to evaluate the practical utility in patients.

In patients on long term treatment serum carbamazepine concentration was determined before starting rectal therapy. Dependent on the time of duration of rectal use, determination of the carbamazepine serum concentration was done daily. Serum samples were collected at $07.00 \mathrm{~h}$ just before the next dose and determined the same day. Determination was performed by an enzyme immune fluorescence assay. The clinical state of the patients was judged by the treating physician. Carbamazepine suppositories were prepared in
Witepsol H15 suppository base (a mixture of saturated triglycerides, melting point $33-36^{\circ} \mathrm{C}$ ).

In all patients therapeutic serum concentrations were reached or maintained and it was possible to control epileptic activity in five patients. One patient was treated unsuccessfully for trigeminal neuralgia, although 'therapeutic' serum concentration was reached. Carbamazepine serum concentrations in relation to rectal dosing of one patient, entering the hospital with an oral dose of $400 \mathrm{mg}$ three times daily, are listed in Table 1.

Carbamazepine suppositories are a useful alternative for oral dosing. The dosage should be titrated individually and it is important to monitor serum concentrations. On the basis of this pilot study we think that further investigating carbamazepine suppositories is worthwhile.

Table 1 The relation between dosage carbamazepine suppositories and carbamazepine serum concentration at $07.00 \mathrm{~h}$.

\begin{tabular}{lcc}
\hline Day & $\begin{array}{c}\text { Dosage carbamazepine } \\
\text { rectally }(\mathrm{mg})\end{array}$ & $\begin{array}{c}\text { Carbamazepine } \\
\text { concentration }\left(m g \mathrm{l}^{-1}\right)\end{array}$ \\
\hline 0 & & 8.2 \\
1 & $3 \times 300$ & 6.5 \\
2 & $4 \times 300$ & 9.9 \\
3 & $4 \times 300$ & 10.1 \\
4 & $2 \times 300$ & 7.1 \\
5 & $3 \times 300$ & 6.9 \\
6 & $3 \times 300$ & 7.7 \\
\hline
\end{tabular}

\section{Pharmacokinetic and dosimetric analysis of $\left[{ }^{186} \mathrm{Re}\right]$ HEDP uptake in bone cancer patients in comparison with $\left[{ }^{89} \mathrm{Sr}\right]$ chloride and $\left[{ }^{153} \mathrm{Sm}\right]$ EDTMP.}

M. W. KONIJNENBERG, G. J. ENSING \& H. H. VAN ROOIJ Mallinckrodt Medical B.V., P.O. Box 3, 1755 ZG Petten, The Netherlands

Rhenium $\left[{ }^{186} \mathrm{Re}\right]$ hydroxyethylidene diphosphonate (HEDP) is a bone pain palliation agent that localises in metastatic bone lesions. Multicompartmental models were applied to the dosimetry data from a dose escalation study of $\left[{ }^{186} \mathrm{Re}\right]$ HEDP. It was found that an extra compartment (metastases) had to be added to the original twocompartment model describing diphosphonate uptake in bone [1]. HEDP is rapidly cleared from the blood: $30 \mathrm{~min}$ after injection $9.3 \pm 4.5 \%$ injected dose (ID) remained in the plasma. After $4 \mathrm{~h}$ this decreases to $3.4 \pm 2.2 \%$ ID and after $24 \mathrm{~h}, 0.9 \pm 0.4 \%$ ID. Clearance through urinary excretion takes place mainly in the first $6 \mathrm{~h}(47 \pm 24 \%$ of the injected radioactivity). Accumulation of ${ }^{186}$ Re-HEDP in metastases is approximately 6 times the uptake in normal bone; however $21 \%$ of the patients showed a metastatic uptake lower or comparable with normal bone.

The bone marrow radiation dose, estimated from the human two-compartment uptake data according to the MIRD scheme, yields $1.3 \mathrm{mGy} / \mathrm{MBq}$. This is low in comparison with the dose for other bone therapy agents at the recommended therapeutically injected activities [2, 3], shown in Table 1. Direct radiotoxicity in the bone marrow cells is described by a dose-effect curve, using $L D_{50}=5.5 \mathrm{~Gy}$ and $L D_{5}=2 \mathrm{~Gy}$ with hypoplasia as end-point [4]. The threshold activities limiting the chance of marrow toxicity to $5 \%$ are $159 \mathrm{MBq}{ }^{89} \mathrm{Sr}, 1295 \mathrm{MBq}{ }^{153} \mathrm{Sm}$ and $1480 \mathrm{MBq}$ ${ }^{186} \mathrm{Re}$.

The pharmacokinetic analysis showed that prediction of the injected activity for therapeutic efficacy is not possible, if based on mean pharmacokinetic modelling. Instead patient-specific dosimetry, based on the individual uptake in painful metastases is recommended. 


\begin{tabular}{lccc}
\hline Target organs & $\begin{array}{c}1295 \mathrm{MBq} \\
{ }^{186} \mathrm{Re}-\mathrm{HEDP}\end{array}$ & $\begin{array}{c}2590 \mathrm{MBq} \\
{ }^{153} \mathrm{Sm} \text {-EDTMP }\end{array}$ & $\begin{array}{c}148 \mathrm{MBq} \\
{ }^{89} \text { Sr-chloride }\end{array}$ \\
\hline Kidneys & & Absorbed dose $(\mathrm{G} Y)$ & \\
Red marrow & 0.46 & $0.047 \star$ & 0.33 \\
Bone surfaces & 1.7 & 4.0 & 1.8 \\
Urinary bladder wall & 4.0 & 18 & 2.0 \\
Effective dose (Sv) & 1.6 & 2.5 & 0.30 \\
\hline
\end{tabular}

Table 1 Radiation dosimetry for bone pain palliation agents.

$\star$ Using kidney clearance based on activity 0-3 min after injection and whole-body clearance.

1 Weber DA, et al. J Nucl Med 1989; 30: 1117.

2 SPC Quadramet. CIS bio international EU/1/97/057/001, 1997.

3 ICRP Publication 53. Radiation dose to patients from radiopharmaceuticals, ed. Nosslin B. Oxford: Pergamon Press, 1987.
4 ICRP Publication 41. Nonstochastic effects of ionizing radiation, ed. Sowby FB. Oxford: Pergamon Press, 1984.

\section{Modulation of intestinal calcium absorption using strontium as a marker}

\author{
M. DIJKGRAAF-TEN BOLSCHER ${ }^{1}$, J. C. NETELENBOS ${ }^{1}$, \\ R. BARTO ${ }^{2} \&$ W. J. F. VAN DER VIJGH ${ }^{2}$ \\ ${ }^{1}$ Department of Endocrinology and ${ }^{2}$ Clin Res. Lab. Int. Med., \\ University Hospital Vrije Universiteit, De Boelelaan 1117, $1081 \mathrm{HV}$ \\ Amsterdam, The Netherlands
}

Various studies have demonstrated a close relationship between the intestinal absorption of calcium (Ca) and strontium (Sr). Therefore, intestinal $\mathrm{Sr}$ absorption is becoming accepted as a clinical and diagnostic tool for measuring intestinal calcium absorption in humans [1]. In the present study, we validated the Sr absorption test for its reproducibility and its sensitivity to the modulating effect of calcitriol. Thereafter we applied this test for investigating the modulating effect of oestrogen on intestinal $\mathrm{Sr}$ absorption in postmenopausal women.

In the first part of the study, intestinal $\mathrm{Sr}$ absorption was assessed in eight healthy men between 20 and 60 years of age. Subjects received $200 \mathrm{ml}$ of a test solution, which contained $2.5 \mathrm{mmol} \mathrm{SrCl}_{2}$. One, 2, 3, and $4 \mathrm{~h}$ after ingestion, a blood sample was withdrawn for the determination of $\mathrm{Sr}$. Fractional absorption $\left(\mathrm{Fc}_{\mathrm{t}}\right)$ and area under the curve $\operatorname{AUC}(0, t)$ were calculated during the first $4 \mathrm{~h}$ after an oral load of $2.5 \mathrm{mmol} \mathrm{SrCl}_{2}$. Two tests were performed with an interval of 10 days for calculating the within-subject coefficient of variation. Prior to the third test, $0.5 \mu \mathrm{g}$ calcitriol was given twice daily for 3 days. The withinsubject coefficient of variation of $\mathrm{Fc}_{240}$ and $\mathrm{AUC}(0,240 \mathrm{~min})$ were $12.3 \%$ and $10.7 \%$, respectively. Calcitriol significantly stimulated intestinal $\mathrm{Sr}$ absorption as was reflected by the
$\mathrm{FC}_{240}$ and $\mathrm{AUC}(0,240 \mathrm{~min}): 35 \%(P=0.003)$ and $61 \%(P=$ $0.001)$, respectively. Although the reproducibility of $\operatorname{AUC}(0,240 \mathrm{~min})$ and its sensitivity to calcitriol were better than those of $\mathrm{Fc}_{240}, \mathrm{Fc}_{240}$ of $\mathrm{Sr}$ was preferred for a clinical test because of its simplicity (two instead of five blood samples).

The second part of the study was performed because a considerable uncertainty exists about the underlying cause of the Ca malabsorption in postmenopausal women. It has been variously attributed to decreased serum calcitriol levels and/or to intestinal resistance to its action. Oestrogen receptors are present in the small intestine [2]. It is therefore quite possible that oestrogen has its own direct action on intestinal cells in concert with calcitriol to stimulate intestinal Ca absorption.

Eight postmenopausal women participated in this study. As in the first study, two baseline $\mathrm{Sr}$ absorption tests were performed. Thereafter the effect of 2 months of oestrogen treatment on $\mathrm{Fc}_{\mathrm{t}}$ and $\mathrm{AUC}(0, t)$ was assessed. The withinsubject coefficients of variation of $\mathrm{Fc}_{240}$ and $\mathrm{AUC}(0,240 \mathrm{~min})$ were $16.9 \%$ and $20.1 \%$, respectively. Oestrogen did not modulate intestinal strontium absorption in these normal postmenopausal women, suggesting that a (supra) physiological dose of oestrogen does not substantially stimulate intestinal calcium absorption in normal postmenopausal women.

It can be concluded that strontium like calcium can be stimulated by calcitriol. Application of the strontium absorption test in postmenopausal women showed that a (supra) physiological dose of oestrogen did not modulate intestinal strontium absorption.

1 Arjmandi BH, et al. Bone and Mineral 1993; $21: 63$.

2 Sips AJAM, et al. Br J Clin Pharmacol 1996; 41: 543. 


\section{Characteristics associated with the development of adverse drug events in hospitalized patients, and their influence on length of hospital stay}

\author{
P. M. L. A. VAN DEN BEMT, A. C. G. EGBERTS ${ }^{1,2}$, A. W. \\ LENDERINK $^{1}$, J. M. VERZIJL ${ }^{1}$, K. A. SIMONS ${ }^{1}$, \\ W. S. C. J. M. VAN DER POL ${ }^{3} \&$ H. G. M. LEUFKENS ${ }^{2}$
} Hospital Pharmacy Medisch Centrum Leeuwarden, Postbus 888, Leeuwarden, ${ }^{1}$ Hospital Pharmacy Midden-Brabant, ${ }^{2}$ Utrecht Institute for Pharmaceutical Sciences, Department of Pharmacoepidemiology and Pharmacotherapy and ${ }^{3}$ Hospital Pharmacy Diagnostisch Centrum SSDZ Delft, The Netherlands

Adverse drug events (ADEs) occur frequently in hospitalized patients [1] and may lead to increased morbidity, mortality and costs [2]. Early detection of ADEs could aid in their prevention. An efficient system for early detection of ADEs should focus on high risk patients.

The primary aim was to identify characteristics that are associated with the development of ADEs in hospitalized patients. A secondary aim was to study whether the development of an ADE during hospitalization was associated with a longer hospital stay.

The study was conducted on the internal medicine wards of two Dutch hospitals. In order to detect ADEs with a high degree of sensitivity, reports of ADEs from doctors, nurses and patients were used. The following determinants

1 Lazarou J, et al. Incidence of adverse drug events in hospitalized patients. A meta-analysis of prospective studies. JAMA 1998; 279: 1200 were analysed for their potential relationship to the occurrence of ADEs: age, gender, number of drugs prescribed during hospital stay, types of drugs used and changes in drug use on admission. Length of hospital stay was analyzed as a possible consequence of the occurrence of ADEs.

A total of 620 patients were included in the study and ADEs were reported in 179 (29\%) of these patients. Age was found to be inversely associated with the development of ADEs (for those aged 60-74 years OR 0.7, 95\% CI $0.4-1.1$ and for those older than 80 years OR 0.4 , 95\% CI 0.2-0.6). Statistically significant associations were also found for the number of drugs prescribed per hospitalized patient (for 4-6 drugs per patient OR 2.6, 95\% CI 1.3-5.2 and for more than 10 drugs per patient: OR 5.0, 95\% CI 2.6-9.8), for newly prescribed drugs (OR 6.7, 95\% CI 2.6-16.8), for the cessation of drugs on hospital admission (OR 1.5, 95\% CI 1.0-2.2) and for the use of gastrointestinal drugs (OR $2.1,95 \%$ CI 1.3-3.5), central nervous system drugs (OR 1.7, 95\% CI 1.1-2.6) and antibiotics (OR 2.4, 95\% CI 1.7-3.6). The development of an ADE was associated with a mean increased length of hospital stay of 2.7 days (95\% CI -1.0 to 6.5$)$.

Number of drugs per patient, changes in drug therapy, use of GI drugs, CNS drugs and antibiotics were associated with an increased risk of ADEs. Age was associated with a decreased risk of ADEs. The duration of hospital stay was on average increased by 2.7 days in patients with ADEs.

2 Classen DC, et al. Adverse drug events in hospitalized patients. JAMA 1997; 277: 301.

\section{Can isoprenaline stimulate in vivo human thermogenesis and lipid utilisation via $\beta_{3}-$ adrenoceptors?}

\section{S. L. H. SCHIFFELERS, E. THIJSSEN, E. E. BLAAK, W. H. M. SARIS \& M. A. VAN BAAK}

NUTRIM, Department of Human Biology, Maastricht University, PO Box 616, 6200 MD Maastricht, The Netherlands

The sympathetic nervous system plays an important role in energy and substrate metabolism. $\beta_{1}$ - and $\beta_{2}$-adrenoceptor stimulation significantly increases thermogenesis, lipid oxidation and lipolysis. The role of the 'atypical' or $\beta_{3}-$ adrenoceptor is still debated since no specific $\beta_{3}$-adrenoceptor agonist is available for infusion in humans. In vitro studies with human isolated fat cells indicate that isoprenaline stimulates $\beta_{1}$ - and $\beta_{2}$-adrenoceptor-mediated lipolysis in the nanomolar dose range, while $\beta_{3}$-adrenoceptor-mediated lipolysis is activated with isoprenaline concentrations in the micromolar range.

The aim of this study was to determine whether isoprenaline in the micromolar range can induce $\beta_{3}-$ adrenoceptor-mediated thermogenesis and lipid utilisation in vivo in humans.

Seven males (age: 20-27 years) participated in this study. Two hours before arrival in the laboratory subjects ingested $80 \mathrm{mg}$ of the $\beta_{1}$ - and $\beta_{2}$-adrenoceptor antagonist nadolol (Corgard ${ }^{\circledR}$, Bristol-Myers Squibb, Germany). On arrival a cannula was inserted into a forearm vein and subjects rested in supine position during the remainder of the test. After a baseline period of $30 \mathrm{~min}$ a continuous infusion of the $\beta_{1^{-}}$, $\beta_{2^{-}}$and $\beta_{3^{-}}$adrenoceptor agonist isoprenaline (isoprenaline sulphate, Fresenius BV, The Netherlands) or saline was started. Isoprenaline was infused in increasing dosages of 50 , 100 and $200 \mathrm{ng} \mathrm{kg}^{-1} \mathrm{~min}^{-1}$, each dosage for $30 \mathrm{~min}$. Saline was administered at the same infusion rates. Energy expenditure and respiratory exchange ratio (RER) were continuously measured by indirect calorimetry and at the 
end of each $30 \mathrm{~min}$ period heart rate and blood pressure were measured and a blood sample was taken. The study design was single blind and the order of treatments was randomised.

After pretreatment with $80 \mathrm{mg}$ nadolol, isoprenaline infusion only caused a significantly higher increase in heart rate as compared with saline infusion (two-way ANOva heart rate by treatment: $P<0.001)$. All other parameters did not differ significantly between treatments although changes in plasma glycerol were lower and changes in systolic blood pressure were greater following isoprenaline.

In conclusion, these data indicate that during infusion of the $\beta_{1^{-}}, \beta_{2^{-}}$and $\beta_{3}$-adrenoceptor agonist isoprenaline with concomitant $\beta_{1}$ - and $\beta_{2}$-adrenoceptor blockade by nadolol no evidence for a $\beta_{3}$-adrenoceptor mediated increase in thermogenesis or lipid utilisation could be found.

\begin{tabular}{|c|c|c|c|c|}
\hline \multirow[b]{2}{*}{ Parameter } & & \multicolumn{3}{|c|}{ Isoprenaline $\left(\mathrm{ng} \mathrm{kg}^{-1} \min ^{-1}\right)$} \\
\hline & & 50 & 100 & 200 \\
\hline \multirow[t]{2}{*}{$\Delta \mathrm{EE}\left(\mathrm{kJ} \min ^{-1}\right)$} & Saline & $0.08 \pm 0.15$ & $-0.21 \pm 0.06$ & $0.27 \pm 0.14$ \\
\hline & Iso & $0.15 \pm 0.12$ & $0.23 \pm 0.11$ & $0.35 \pm 0.21$ \\
\hline \multirow[t]{2}{*}{$\Delta$ RER } & Saline & $-0.01 \pm 0.01$ & $-0.02 \pm 0.01$ & $-0.02 \pm 0.01$ \\
\hline & Iso & $-0.02 \pm 0.01$ & $-0.04 \pm 0.01$ & $-0.03 \pm 0.02$ \\
\hline \multirow[t]{2}{*}{$\Delta$ FFA $\left(\mu \mathrm{moll}^{-1}\right)$} & Saline & $21 \pm 33$ & $93 \pm 54$ & $100 \pm 65$ \\
\hline & Iso & $31 \pm 34$ & $98 \pm 42$ & $178 \pm 58$ \\
\hline \multirow[t]{2}{*}{$\Delta$ Glycerol $\left(\mu \mathrm{moll}^{-1}\right)$} & Saline & $3.19 \pm 2.69$ & $11.25 \pm 5.04$ & $18.86 \pm 6.97$ \\
\hline & Iso & $-6.02 \pm 4.19$ & $0.91 \pm 4.19$ & $4.99 \pm 5.87$ \\
\hline \multirow[t]{2}{*}{$\Delta \operatorname{HR}$ (beats $\min ^{-1}$ ) } & Saline & $0 \pm 1$ & $0 \pm 1$ & $-2 \pm 1$ \\
\hline & Iso & $4 \pm 1$ & $6 \pm 1$ & $8 \pm 1$ \\
\hline \multirow[t]{2}{*}{$\Delta \mathrm{SYS}(\mathrm{mmHg})$} & Saline & $0 \pm 2$ & $0 \pm 2$ & $2 \pm 5$ \\
\hline & Iso & $4 \pm 3$ & $9 \pm 5$ & $15 \pm 6$ \\
\hline
\end{tabular}

Table 1 Changes in measured parameters during isoprenaline (iso) or saline infusion after pretreatment with $80 \mathrm{mg}$ nadolol.

Mean \pm s.e. mean, $n=7$. EE: energy expenditure, FFA: free fatty acids, HR: heart rate,

SYS: systolic blood pressure.

\section{The acute effects of a single supratherapeutic dose of inhaled salbutamol on lung function and endurance performance in well-trained, non-asthmatic athletes}

O. M. DE $\mathrm{HON}^{1}$, F. HARTGENS ${ }^{1,2}$, M. A. VAN BAAK ${ }^{3}$, L. J. R. M. BUISMAN ${ }^{1} \&$ G. RIETJENS ${ }^{1,2}$

${ }^{1}$ Netherlands Centre for Doping Affairs, PO Box 4060, 3006 AB Rotterdam, ${ }^{2}$ Department of Movement Science, Mastricht University, PO Box 616, 6200 MD Maastricht and ${ }^{3}$ Department of Human Biology, Maastricht University, PO Box 616, 6200 MD Maastricht, The Netherlands

The $\beta_{2}$-adrenoceptor agonist salbutamol is one of the most widely used drugs to treat asthma. Because of its bronchodilatory and systemic effects, salbutamol is also thought to enhance athletic performance. The literature about this subject is inconclusive, but studies have not used doses above the maximal therapeutic dose in the general treatment of asthma ( $400 \mu \mathrm{g}$ by inhalation or $4 \mathrm{mg}$ orally). It is questionable whether athletes who consider the use of a $\beta_{2^{-}}$ agonist as an ergogenic aid would restrict themselves to such dosages. In order to come to a more appropriate conclusion regarding the possible ergogenic effects of salbutamol, the effects of supratherapeutic doses on athletic performance should be studied.

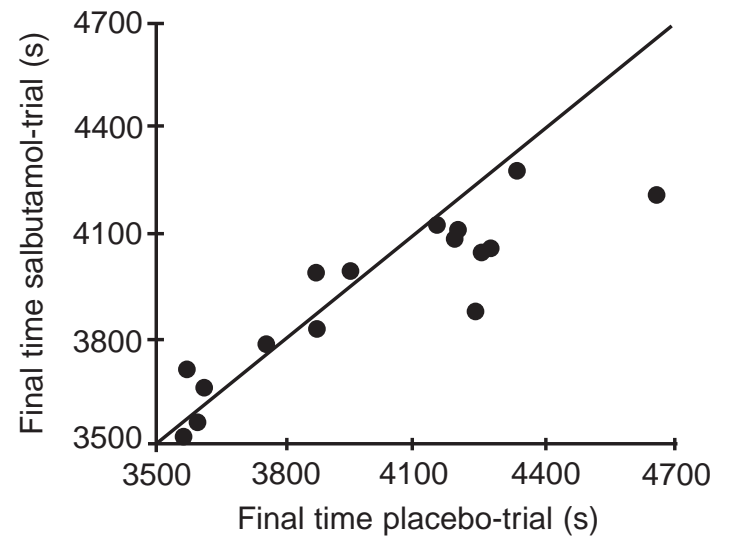

Figure 1 Individual results of the time trials. Each dot represents one subject.

This study examined the effects of a single supratherapeutic dose $(800 \mu \mathrm{g})$ salbutamol and placebo, by inhalation on lung function and endurance performance.

Sixteen well-trained male cyclists and triathletes $(23 \pm 3$ years of age, $11.2 \pm 3.4 \mathrm{~h}$ of training per week; mean \pm s.d.) participated in this study. All participants were nonasthmatic, as confirmed by an exercise provocation test. The study was performed according to a double-blind, 
randomized, placebo controlled cross-over design. Exercise performance was measured by means of a time trial on a magnetically braked cycle ergometer (Lode, The Netherlands). The following lung function parameters were measured using a Microspiro Hi-298 (Chest, Japan): peak expiratory flow (PEF), $1 \mathrm{~s}$ value of forced expiratory volume $\left(\mathrm{FEV}_{1}\right)$, forced ventilatory capacity $(\mathrm{FVC})$, and $\mathrm{FEV}_{1} / \mathrm{FVC}$.

Inhalation of salbutamol improved the average time to complete the time trial in comparison with placebo $(3928 \pm 231$ vs $4010 \pm 328$ s respectively). A one-tailed $t$-test showed that this improvement was significant $(P<0.03)$. The individual results hint that the ergogenic effects of salbutamol are mainly present in those subjects who perform relatively poorly (see Figure 1).
Forced ventilatory capacity (FVC) was not affected by salbutamol. Salbutamol did significantly increase PEF, FEV 1 , and $\mathrm{FEV}_{1} / \mathrm{FVC}$ before exercise; PEF remained elevated after completion of the test (1 min post-exercise).

This study shows that the expiratory flow of healthy subjects at rest and after completion of an endurance test is increased after the administration of a single $800 \mu \mathrm{g}$ dose of salbutamol. The results of this study also suggest that salbutamol can increase endurance performance in welltrained, non-asthmatic athletes. This ergogenic effect could depend on the performance level of the athlete. The mechanism responsible for these performance enhancing effects of salbutamol remains to be determined.

\section{Relationship of exposure to nevirapine to clearance rate and likelihood to reach an undetectable HIV-1 RNA copy number in plasma after 52 weeks}

\author{
A. I. VELDKAMP ${ }^{1}$, R. M. W. HOETELMANS ${ }^{1}$, J. H. \\ BEIJNEN $^{1}$, and the investigators of the INCAS Trial Group \\ ${ }^{1}$ Department Pharmacy and Pharmacology, Slotervaart Hospital, \\ Amsterdam, The Netherlands
}

Relationships have been described between the exposure to protease inhibitors and the initial and long-term virologic response in HIV-1-infected individuals. Data from the INCAS trial were used to explore such relationships for a nonnucleoside reverse transcriptase inhibitor, nevirapine (NVP). INCAS was a double-blind, randomized, multicentre study (151 patients) in which three combination regimens were compared: AZT/NVP, AZT/ddI, and AZT/ddI/NVP. The triple arm was used for this analysis (51 patients). The initial HIV-1 clearance rate in plasma $(k)$ during the first 2 weeks of therapy was calculated using the equation $V_{t}=V_{0} \star^{\left(-k^{\star} t\right)}$ where $V_{0}$ and $V_{\mathrm{t}}$ represent plasma HIV-1 RNA in copies $/ \mathrm{mL}$ at baseline and at time $t$, respectively, $k$ is the elimination rate constant $\left(\right.$ day $\left.^{-1}\right)$, and $t$ is the time after start of therapy (days). Linear regression analyses were performed using $k$ as the dependent variable, and the median NVP plasma concentration during the first 2 weeks, the baseline CD4+ count and baseline HIV-1 RNA ( $\log _{10}$ units) as independent covariates. Logistic regression analyses were performed with the reaching of undetectability for HIV-1 RNA in plasma $\left(<20\right.$ copies $\left.\mathrm{ml}^{-1}\right)$ after 52 weeks and the median NVP plasma concentration after $2,4,12,24,36$, and 52 weeks, the baseline CD4 + count and baseline HIV-1 RNA $\left(\log _{10}\right.$ units) as independent covariates [intention-to-treat analysis (missing value equals failure)]. Linear regression analyses were also performed with the duration of virologic response number of days with HIV-1 RNA in plasma $<500$ copies $\mathrm{ml}^{-1}$ ) as the dependent variable, and baseline HIV-1 RNA ( $\log _{10}$ units), $k$, and the median NVP concentration during 52 weeks as independent variables. The median HIV-1 clearance rate was 0.29 day $^{-1}$ (IQR 0.20-0.34). Multivariate linear regression analyses revealed that the median NVP plasma concentration during the first 2 weeks and the baseline plasma HIV-1 RNA are significantly and positively related with $k, P=0.011$ and 0.008 , respectively. From week 12, the median NVP concentration was related significantly with the probability to reach undetectable HIV-1 RNA in plasma at week 52. A higher median NVP concentration after 24 weeks (median NVP plasma concentration $3.69 \mu \mathrm{g} \mathrm{ml}^{-1}$ ) of treatment resulted in a higher chance to become undetectable for plasma HIV-1 RNA after 52 weeks of therapy with NVP, AZT, and ddI (OR 1.56, range 1.06-2.29). The median NVP plasma concentration during the study period was positively and significantly related with the duration of virologic response $(P=0.0056)$. These analyses show that a higher exposure to NVP is associated with a more rapid initial clearance rate of HIV-1 RNA from plasma, a higher chance to reach an undetectable HIV-1 RNA copy number in plasma after 52 weeks of therapy, and a more sustained suppression of HIV-1 replication. 


\section{Phase I and pharmacokinetic study: pharmacological modulation of ifosfamide with inhibitors and stimulators of the $\mathbf{P 4 5 0}$ cytochrome system}

T. KERBUSCH ${ }^{1}$, R. L. H. JANSEN ${ }^{2}$, A. D. R. HUITEMA ${ }^{1}$, J. H. M. SCHELLENS ${ }^{1}$, M. JANSEN ${ }^{2}$, R. E. N. VAN RIJSWIJK $^{2} \&$ J. H. BEIJNEN ${ }^{1}$

${ }^{1}$ The Netherlands Cancer Institute, Amsterdam and ${ }^{2}$ Academic Hospital Maastricht, Maastricht, The Netherlands

Ifosfamide (IF) is a prodrug requiring activation through 4-hydroxyIF (4OHIF) to ifosforamide mustard, to exert cytotoxicity. Deactivation of IF leads to 2- and 3-dechloroethylIF (2DCE, 3DCE) and the release of potentially neurotoxic chloroacetaldehyde. Both metabolic routes (hydroxylation and $\mathrm{N}$-dechloroethylation) are mediated by CYP3A4. IF metabolism exhibits autoinduction (AI). Sixteen patients received $3 \mathrm{~g} \mathrm{IF} \mathrm{m}^{-2} 24 \mathrm{~h}^{-1}$ i.v. and were subjected to plasma and urine sampling. Each patient received two courses with a 3 week interval. Patients were randomised to receive ketoconazole (KETO) or rifampicin (RIF), randomly in the first or second course. KETO and RIF are a potent inhibitor and inducer of CYP3A4, respectively. The aim of the study was to evaluate the influence/benefit of modulation of the IF metabolism. A sequential pharmacokinetic model is represented including the AI for all individual PK curves using NONMEM in Table 1.

Including AI for all metabolite models proved to be superior. IF clearance $\left(\mathrm{CL}_{(\mathrm{t}) \text {,ifo }}\right)$ and volume of distribution $\left(V_{\text {ifo }}\right.$ ) were used as posthoc estimations for the metabolite model in order to include the autoinduced $\mathrm{CL}_{(\mathrm{t}) \text {,ifo }}$ as shown in Table 2. $\mathrm{F} / V_{\mathrm{m}}$ was the fraction metabolised, A the amount and $K_{m}$ the elimination constant.

Parameters, noncompartmental AUCs and total urine excretion (UE) were obtained from 10 patients. Assuming $V_{\mathrm{m}}$ was unaffected, the change in $\mathrm{F} / V_{\mathrm{m}}$ was an estimate of increase of metabolic formation rate. KETO only affected $V_{\text {ifo }}(-8 \%$ due to modulator $)$ and $\mathrm{UE}_{2 \mathrm{dce}}(+13 \%)$ insignificantly $(P<0.1, n=5)$. RIF did significantly increase $\mathrm{CL}_{\text {ini,ifo }}(+120 \%)$ resulting in increased $K_{m, 2 \mathrm{dce}}(+57 \%)$, $K_{m, 3 \mathrm{dce}}(+79 \%)$ and $\mathrm{F} / V_{\mathrm{m}, 3 \mathrm{dce}}(+53 \%) \quad(P<0.1, n=5)$. Consequently decreased exposure of IF $(-50 \%)$ and $2 \mathrm{DCE}$ $(-29 \%)$ and not 3DCE and 4OHIF was observed. Furthermore, RIF decreased $\mathrm{UE}_{\text {ifo }}(-37 \%)$ and increased $\mathrm{UE}_{3 \mathrm{dce}}(+27 \%)$. The individual NONMEM model enabled evaluation of various shifts in IF metabolism due to CYP3A4 modulation.

\begin{tabular}{|c|c|c|c|}
\hline$P K$ & & Estimation & Differential equation \\
\hline $\mathrm{CL}_{(\mathrm{t}) \mathrm{ifo}}$ & $\left(1 \mathrm{~h}^{-1}\right)$ & $\theta_{1 \mathrm{i}}+\theta_{1 \mathrm{i}}{ }^{\star}\left(1-\mathrm{e}^{-\theta 2 \mathrm{i} \star \text { time }}\right)$ & $\mathrm{dA}_{1} / \mathrm{dt}=-\mathrm{CL}_{(\mathrm{t}) \mathrm{ifo}} \star \mathrm{A}_{\mathrm{if}} / V_{\mathrm{ifo}}$ \\
\hline $\mathrm{CL}_{\text {ini,ifo }}$ & $\left(1 \mathrm{~h}^{-1}\right)$ & $\theta_{1 \mathrm{i}}$ & \\
\hline$V_{\text {ifo }}$ & (1) & $\theta_{3 \mathrm{i}}$ & \\
\hline$K_{\text {enz }}$ & $\left(\mathrm{h}^{-1}\right)$ & $\theta_{2 \mathrm{i}}$ & \\
\hline
\end{tabular}

Table 1

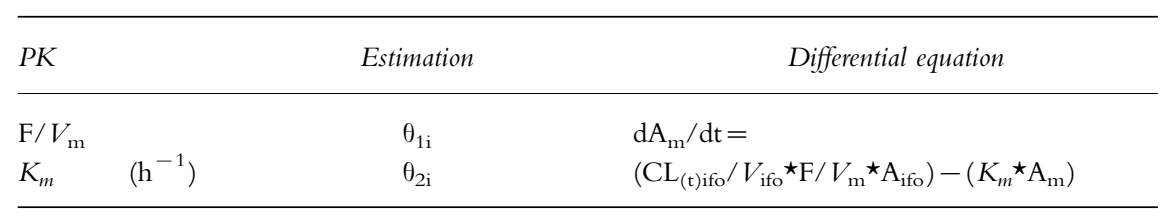

Table 2

\section{Influence of cyclosporin A on the oral bioavailability of docetaxel in cancer patients}

M. M. MALINGRÉ, D. J. RICHEL ${ }^{1}$, W. W. TEN BOKKEL HUININK, M. SCHOT, H. ROSING, J. H. BEIJNEN \& J. H. M. SCHELLENS

The Netherlands Cancer Institute, Amsterdam and ${ }^{1}$ Medisch Spectrum Twente, Enschede, The Netherlands

The oral bioavailability of the anticancer drug docetaxel is very low, due to its high affinity for the drug efflux pump $\mathrm{P}$-glycoprotein (P-gp), abundantly present in the gastrointestinal tract. Based on our preclinical research, with mdr1ab
P-gp deficient double knockout mice, oral administration of docetaxel plus the P-gp inhibitor cyclosporin A (CsA) should increase systemic exposure of docetaxel to therapeutic levels.

A proof of concept study was carried out in 14 patients with solid tumours. Four patients received $75 \mathrm{mg} \mathrm{m}^{-2}$ of oral docetaxel (Taxotere ${ }^{\circledR}$ ) without CsA during course 1 and standard $100 \mathrm{mg} \mathrm{m}^{-2}$ docetaxel i.v. all other courses. Ten other patients received oral docetaxel plus $15 \mathrm{mg} \mathrm{kg}^{-1}$ oral CsA $\left(\mathrm{Neoral}{ }^{\circledR}\right.$ capsules) and all other courses i.v. docetaxel. The second course was randomised with the first course. CsA preceeded docetaxel by $30 \mathrm{~min}$. Oral drugs were taken with $100 \mathrm{ml}$ tap water after an overnight fast. 
Standard docetaxel pretreatment, consisting of oral dexamethasone, was given for all courses. The pharmacokinetics of docetaxel and CsA were determined during course 1 and 2 using validated assays.

Patients (4 males, 10 females) had a median age of 50 years (range 31-71) and median WHO performance score of $1(0-2)$. The tumour types were breast (7), non-small cell lung cancer (3), small cell lung cancer (1), oesophagus (1), stomach (1) and adenocarcinoma of unknown primary site (1). The mean area under the concentration-time curve (AUC) in patients who received $75 \mathrm{mg} \mathrm{m}^{-2}$ oral docetaxel as a single agent was $0.46 \pm 0.41 \mu \mathrm{M} \mathrm{h}$ and $3.36 \pm 2.25 \mu \mathrm{M} \mathrm{h}$ for oral docetaxel with CsA $(P<0.01)$. The mean AUC of $100 \mathrm{mg} \mathrm{m}^{-2}$ i.v. docetaxel was $5.48 \pm 2.60 \mu \mathrm{M} \mathrm{h}$. The bioavailability of oral docetaxel was $8 \pm 5 \%$ without and
$90 \pm 44 \%$ with CsA. CsA reached therapeutic levels. Besides a poor taste, the oral combination was well tolerated and induced no nausea, vomiting or diarrhoea. A common docetaxel pattern of toxicity developed after the i.v. courses.

In conclusion, co-administration of oral CsA resulted in a pronounced increase in the systemic exposure of oral docetaxel. In combination with CsA the bioavailability of oral docetaxel was nearly complete. Furthermore, interpatient variability was similar for oral and i.v. administered docetaxel. These data are very promising for the development of a clinically useful oral formulation of this cytostatic drug. A phase II study in patients with advanced breast cancer aimed at assessment of the antitumour activity of the weekly oral combination of CsA and docetaxel is currently ongoing.

\section{CYP2C9 polymorphism and dose requirement of acenocoumarol}

INGE VERKOOIJEN ${ }^{1}$, HERMAN FRANK ${ }^{2} \&$ HENK THIJSSEN $^{1}$

${ }^{1}$ Department of Pharmacology, University of Maastricht and

${ }^{2}$ Thrombosis Center, Maastricht, The Netherlands

Acenocoumarol is widely used in The Netherlands as an oral anticoagulant. For the majority of patients a daily dose of $2-4 \mathrm{mg}$ is required to maintain the therapeutic target of anticoagulation. There are, however, patients requiring $1 \mathrm{mg}$ or less and patients requiring $7 \mathrm{mg}$ or more daily. The anticoagulant is applied as a racemic mixture. The S-enantiomer is rapidly eliminated implying that the activity is mainly due to (R)-acenocoumarol. Elimination is only by biotransformation, mainly cytochrome P450 mediated hydroxylation reactions. The cytochrome $\mathrm{P} 450$ s responsible for acenocoumarol hydroxylation are CYP2C9 (both the enantiomers) and CYP2C19 ((R)-acenocoumarol). Of both these cytochrome $\mathrm{P} 450$ enzymes allele variants are known having lower activities (CYP2C ${ }^{\star} 2$ and $\star 3$ ) or being inactive $(\mathrm{CYP} 2 \mathrm{C} 19 \star 2$ and $\star 3)$ in in vitro expressed systems. The aim of this study was to determine if CYP2C9 or CYP2C19 polymorphism is associated with acenocoumarol therapeutic dose requirement. Patients on acenocoumarol therapy attending thromboses service centres were recruited. Inclusion criteria were: age less than 70 years, stable anticoagulation, and absence of interfering co-medication. The patients were divided into three groups: requiring daily $1 \mathrm{mg}$ or less (L), 2-5 $\mathrm{mg}(\mathrm{M})$, and $7 \mathrm{mg}$ or more $(\mathrm{H})$, respectively. Blood was collected for genotyping and acenocoumarol analysis. Genotyping was done by PCR analysis [1, 2]. The study had the approval of the Medical
Table 1

\begin{tabular}{|c|c|c|c|c|c|}
\hline & & $L(\mathrm{n}=11)$ & $M(\mathrm{n}=9)$ & $H(\mathrm{n}=6)$ & $t$ \\
\hline Age (years) & & $65.6 \pm 4.2$ & $60.4 \pm 6.2$ & $55.5 \pm 11.7$ & $S^{1}$ \\
\hline Daily dose & $n g)$ & $0.84 \pm 0.1$ & $2.0 \pm 0.0$ & $9.1 \pm 1.5$ & \\
\hline СYР2C9 & $\mathrm{wt} / \mathrm{wt}$ & 3 & 5 & 6 & \\
\hline & $\mathrm{wt} / \star 2$ & 2 & 4 & 0 & \\
\hline & $w t / \star 3$ & 5 & 0 & 0 & \\
\hline & $\star 2 / \star 3$ & 1 & 0 & 0 & \\
\hline CYP2C19 & wt/wt & 8 & 6 & 5 & NS \\
\hline & $\mathrm{wt} / \star 2$ & 3 & 2 & 1 & \\
\hline & $\star 2 / \star 2$ & 0 & 1 & 0 & \\
\hline
\end{tabular}

†Kruskal-Wallis test: 1) L $v s \mathrm{H}, P=0.049 .2) \mathrm{CYP} 2 \mathrm{C} 93, \mathrm{~L} v s \mathrm{M}$ and $\mathrm{H}, P<0.05$.

Ethics Committee. Twenty-six patients enrolled in the study: 11 in the L, 9 in the $M$, and 6 in the $H$ group. The allele CYP2C9 $\star 3$ was found to be present in 6 subjects of $\mathrm{L}(54 \%)$, but in none of the $\mathrm{M}$ and $\mathrm{H}$ subjects, $P=0.006$. No statistical differences between the groups for CYP2C $9 \star 2$ and CYP2C19 2 frequencies were found (Table 1).

(S)-acenocoumarol was detected in 6 subjects of group L, in none of group $\mathrm{M}$ and in one of group $\mathrm{H}$. The presence of $(\mathrm{S})$-acenocoumarol in group $\mathrm{L}$ coincided four times with the CYP2C9 3 allele. Plasma levels of (R)-acenocoumarol were $\left(\mathrm{ng} \mathrm{ml}^{-1}\right): 15.9 \pm 5.3,24.4 \pm 10.3$, and $37.9 \pm 24.1$ for groups $\mathrm{L}, \mathrm{M}$, and $\mathrm{H}$, respectively. There is a strong association between the CYP2C9 3 allele and requirement for low therapeutic acenocoumarol doses. This indicates that impaired metabolism underlies the high sensitivity for the drug. Impairment of (S)- rather than (R)-acenocoumarol metabolism seems to be involved. 


\section{Pharmacokinetics of the apoptotic marker 99mTc-iminothiolane-Annexin $\mathrm{V}$ in seven patients with myocardial infarction and one healthy volunteer}

\author{
H. H. BOERSMA ${ }^{1,2}$, I. H. LIEM ${ }^{1}$, L. HOFSTRA ${ }^{3}$, P. LUX ${ }^{4}$, \\ W. L. VAN HEERDE ${ }^{4}$, P. A. F. DOEVENDANS ${ }^{3}$, L. M. L. \\ STOLK $^{2}$, A. J. BEYSENS ${ }^{2}$, G. J. KEMERINK ${ }^{1}$, C. P. M. \\ REUTELINGSPER GER ${ }^{4} \&$ G. A. K. HEIDENDAL ${ }^{1}$ \\ ${ }^{1}$ Department of Nuclear Medicine, ${ }^{2}$ Department of Clinical \\ Pharmacy and Toxicology, ${ }^{3}$ Department of Cardiology, University \\ Hospital Maastricht, P.O. Box 5800, NL-6202 AZ Maastricht, and \\ ${ }^{4}$ Department of Biochemistry, Cardiovascular Research Institute, \\ University of Maastricht, P.O. Box 616, 6200 MD Maastricht, \\ The Netherlands
}

Apoptosis, programmed cell death, occurs in both physiological and pathological processes, e.g. myocardial infarction. During the apoptotic process, externalisation of phosphatidylserine on the outer side of the cell membrane is regarded as one of the earliest events. Annexin V (MW: $36 \mathrm{kD}$ ) is a physiologically occurring protein with a high, $\mathrm{Ca}^{2+}$ dependent, affinity for phosphatidylserine. It has been used successfully to detect early stages of apoptosis in vitro and in animal models. 99mTc-iminothiolane-Annexin V (Tc-i$\mathrm{AnnV}$ ) has been proven to exert equal affinity for phosphatidyl- serine as the physiological annexine, and is tested for diagnostic use.

This study describes the pharmacokinetics and imaging feasibility of administered Tc-i-AnnV.

Tc-i-AnnV (1 mg, $555 \pm 89 \mathrm{MBq})$ was administered intravenously to seven patients with myocardial infarction, and subsequent reperfusion. Also, one healthy volunteer was investigated. Both $99 \mathrm{mTc}$-radioactivity in blood and plasma as well as the plasma concentration of Tc-i-AnnV antigen was measured until $4 \mathrm{~h}$ after administration. Pharmacokinetic parameters were calculated by non-linear regression analysis using a weighted least-square simplex algorithm (MW/Pharm 3.15 E, The Netherlands).

Pharmacokinetics of Tc-i-AnnV could be described using a two compartment model. Pharmacokinetic parameters are shown in Table 1. Evaluation of the obtained scintigrams revealed that $\mathrm{Tc}-\mathrm{i}-\mathrm{AnnV}$ accumulated in the kidney as well as the liver. In urine, small amounts of Tc-i-AnnV could be detected.

Because the injected amount of Tc-i-AnnV is small in comparison with the endogenous annexin levels, it was impossible to calculate pharmacokinetics in the second compartment. No side-effects were observed. The rapid distribution and a short first compartment half-life time indicate that $\mathrm{Tc}-\mathrm{i}-\mathrm{AnnV}$ is feasible to perform gamma camera imaging of target organs, after intravenous administration.

Table 1 Pharmacokinetic parameters of $99 \mathrm{mTc}$ radioactivity and Tc-i-Ann V concentrations measured in eight individuals. Data are presented as mean \pm s.d.

\begin{tabular}{lccccc}
\hline $\begin{array}{l}\text { Parameter } \\
\text { type of measurement }\end{array}$ & $\begin{array}{c}\mathrm{t}_{1 / 2, \alpha} \\
(\mathrm{min})\end{array}$ & $\begin{array}{c}\mathrm{t}_{1 / 2, z} \\
(\mathrm{~h})\end{array}$ & $\begin{array}{c}\mathrm{V}_{a} \\
(l)\end{array}$ & $\begin{array}{c}A U C(0,4 h) \\
\left(M B q l^{-1} h\right)\end{array}$ & $\begin{array}{c}C L \\
\left(l h^{-1}\right)\end{array}$ \\
\hline $99 \mathrm{mTc}$-radioactivity, plasma & $12 \pm 7$ & $4.6 \pm 1.5$ & $3.8 \pm 0.9$ & $539 \pm 259$ & $1.3 \pm 0.4$ \\
$99 \mathrm{mTc}-$ radioactivity, blood & $13 \pm 6$ & $4.1 \pm 1.4$ & $5.9 \pm 1.6$ & $323 \pm 174$ & $2.0 \pm 0.8$ \\
Annexine V-antigen, plasma & $16 \pm 7$ & Incalculable & Incalculable & Incalculable & Incalculable \\
\hline
\end{tabular}

\section{Influence of theophylline on AP5A-induced vasodilation in the human forearm vascular bed}

E. VAN GINNEKEN, G. A. RONGEN \& P. SMITS ${ }^{1}$

Department of Internal Medicine and ${ }^{1}$ Department of Pharmacology, University Hospital Nijmegen, PO Box 9101, 6500 HB Nijmegen, The Netherlands

In animals, diadenosine pentaphosphate (AP5A) is a potent endogenous vasoconstrictor substance both in vitro and in vivo [1]. Increased levels of AP5A in thrombocytes have been related to the development of essential hypertension
$[2,3]$. In this study we explored the vasomotor action of AP5A in humans in vivo.

In six healthy male volunteers, the brachial artery was cannulated to infuse AP5A, adenosine and ATP successively, and to measure mean arterial blood pressure (MAP) continuously. The vasomotor actions of AP5A, adenosine and ATP were compared $\left(0.6,6\right.$ and $20 \mathrm{nmol} / 100 \mathrm{ml}^{-1}$ forearm volume $\min ^{-1}, 5 \mathrm{~min}$ per dose). Infusion was kept at a constant rate of $50 \mu \mathrm{l}$ forearm min ${ }^{-1}$. Forearm blood flow (FBF) was measured by strain-gauge plethysmography. Forearm vascular resistance (FVR) was calculated as the coefficient of MAP and FBF and expressed in arbitrary units $(\mathrm{AU})$. The vascular response was expressed as percentage change from baseline in forearm vascular resistance (Table 1).

Thus, intra-arterial AP5A significantly reduced vascular 
Table 1 Percentage change from baseline in FVR in response to AP5A, adenosine and ATP (mean \pm s.e.mean). Doses are in nmol $100 \mathrm{ml}^{-1}$ forearm $\mathrm{min}^{-1}$.

\begin{tabular}{lrcc}
\hline $\mathrm{n}=6$ & 0.6 & 6 & 20 \\
\hline AP5A \#^ & $-14 \pm 5$ & $-54 \pm 5$ & $-70 \pm 3$ \\
Adenosine \# & $13 \pm 8$ & $-32 \pm 5$ & $-61 \pm 6$ \\
ATP \# & $-63 \pm 4$ & $-77 \pm 4$ & $-82 \pm 4$ \\
\hline
\end{tabular}

^Indicates significant difference from ATP; \#indicates significant change from baseline $(P<0.05$; Wilcoxon signed-ranks test on the averaged response).

tone. At equimolar infusion rates, AP5A was equipotent to adenosine, but less potent than ATP. In the control arm, no significant changes in vascular tone were observed. To characterize further the unexpected vasodilator response to AP5A, we studied the vasomotor action of AP5A in 10 volunteers before and during intra-arterial infusion of the

1 Flores NA, et al. Cardiovasc Res 1999; 42: 15.

2 Agha A, et al. J Vasc Res 1992; 29: 281.
$\mathrm{P}_{1}$-receptor antagonist theophylline $\left(50 \mu \mathrm{g} \quad 100 \mathrm{ml}^{-1}\right.$ forearm $\min ^{-1}$ ). Theophylline did not significantly affect baseline vascular tone $(26 \pm 4$ vs $21 \pm 2 \mathrm{AU})$.

In the human forearm, intra-arterial AP5A induces vasodilation which is probably mediated by its degradation products. Direct stimulation of $\mathrm{P}_{1}$-receptors cannot be excluded by these results.

Table 2 Percentage change from baseline in FVR (mean \pm s.e. mean) for AP5A during saline and theophylline respectively.

\begin{tabular}{lccc}
\hline $\mathrm{n}=10$ & 0.6 & 6 & 20 \\
\hline AP5A/saline $0.9 \%$ & $-8 \pm 6 \%$ & $-50 \pm 6 \%$ & $-68 \pm 4 \%$ \\
AP5A/theophylline & $-7 \pm 4 \%$ & $-33 \pm 5 \%$ & $-45 \pm 6 \%$ \\
\hline
\end{tabular}

$\star$ Theophylline significantly reduced the area under the dose-response curve $(P<0.05$; Wilcoxon signed ranks test $)$.

3 Schlüter H, et al. Nature 1994; 367: 186.

\section{Meropenem pharmacokinetics and pharmacodynamics in patients with ventilator associated pneumonia}

\author{
F. DE STOPPELAAR, L. STOLK, F. VAN TIEL ${ }^{1}$, A. BEYSENS, \\ S. VAN DER GEEST ${ }^{2} \&$ P. DE LEEUW ${ }^{2}$ \\ Departments of Clinical Pharmacy, ${ }^{1}$ Microbiology and ${ }^{2}$ Internal \\ Medicine, University Hospital of Maastricht, PO Box 5800, 6202 \\ AZ, Maastricht, The Netherlands
}

The aim of this study was the determination of pharmacokinetic and pharmacodynamic parameters of meropenem in patients with ventilator associated pneumonia (VAP).

Data are expressed as mean (s.d.) unless stated otherwise. Eight male intensive care patients, diagnosed with VAP, were included in this study: age 55 (8) years, weight 73 (11) $\mathrm{kg}$, creatinine clearance 85 (26) $\mathrm{ml} \mathrm{min}^{-1}$. A $1 \mathrm{~g}$ meropenem dose (7 min infusion in $50 \mathrm{ml} \mathrm{NaCl} 0.9 \%$ ) was given every $8 \mathrm{~h}$ during a 3-12 day period. Plasma concentrations were determined daily just before (trough) and $0.5 \mathrm{~h}$ after administration (peak). On the second day a plasma concentration curve was determined. Plasma concentrations were measured with a validated h.p.l.c. assay with automatic sample preparation by column switching, developed in our laboratory. Qualitative and semi quantitative cultures of tracheal aspirate were performed daily. MIC determinations were performed on all isolates. Pharmacokinetic parameters were calculated by non linear regression analysis using a weighted least-square simplex algorithm (MW/Pharm 3.15E, The Netherlands).

The mean pharmacokinetic and pharmacodynamic parameters are demonstrated in Table 1.

For all patients a better 'fit' was observed with a 3 than a 2 compartment model; in $5 / 8$ cases with statistical significance $(P<0.05)$. Peak and trough concentrations were 32.9 (11.3) and 3.3 (3.5) respectively $(n=8)$. For $4 / 5$ of the patients with 12 days treatment, there was a decline of peak and trough plasma concentrations: 29.5/3.8 (day 2) and 25.8/0.7 (day 12). The following isolates were cultured as causative agents of VAP: Pseudomonas aeruginosa 5; Haemophilus influenzae 2, Escherichia coli 1. MIC for all initial isolates was $\leq 2 \mathrm{mgl}^{-1}$. In subsequent isolates cultured during therapy, elevated MIC values for meropenem were

\section{Table 1}

\begin{tabular}{|c|c|c|}
\hline Parameter & Mean & s.d. \\
\hline $\mathrm{CL}\left(1 \mathrm{~h}^{-1}\right)$ & 11.0 & 4.3 \\
\hline$V_{\mathrm{ss}}(1)$ & 34.4 & 15.9 \\
\hline$V_{c}(1)$ & 6.4 & 2.9 \\
\hline$t_{1 / 2, \lambda_{1}}(\mathrm{~h})$ & 0.049 & 0.025 \\
\hline$t_{1 / 2, \lambda_{2}}(\mathrm{~h})$ & 0.374 & 0.124 \\
\hline$t_{1 / 2, \lambda_{3}}(\mathrm{~h})$ & 3.08 & 1.7 \\
\hline $\operatorname{AUC}(0,8 \mathrm{~h})\left(\mathrm{mg} \mathrm{l}^{-1} \mathrm{~h}\right)$ & 102.7 & 42.9 \\
\hline $\mathrm{AUC}_{\mathrm{ss}}(0,24 \mathrm{~h}) / \mathrm{MIC}(\mathrm{h})$ & 154.1 & 64.3 \\
\hline AUIC (h) & 152.5 & 66 \\
\hline T > MIC (\%) & 90.8 & 13.4 \\
\hline
\end{tabular}


found in $3 / 5$ patients with a Pseudomonas VAP. However we found no clear association with pharmacokinetic data.

We observed a three compartment model, not reported earlier. CL was lower and $V_{\text {ss }}$ higher when compared with data from healthy volunteers. CL was equal and $V_{\text {ss }}$ even higher than found in a recent study with critically ill patients [1]. Development of resistance throws possible doubt on the present dosage scheme. More data are needed to elucidate possible relationship with the pharmacokinetic data.

\section{Low dose bromide as a marker of patient compliance}

\author{
S. H. M. VAN UUM ${ }^{1}$, W. H. DOESBURG ${ }^{2}$, D. W. \\ SWINKELS $^{3}$, F. G. M. RUSSEL ${ }^{4} \&$ TH. THIEN ${ }^{1}$ \\ Departments of ${ }^{1}$ General Internal Medicine and ${ }^{3}$ Clinical \\ Chemistry, University Hospital Nijmegen and ${ }^{2}$ Medical Statistics \\ and ${ }^{4}$ Pharmacology, Faculty of Medical Sciences, Nijmegen, The \\ Netherlands
}

Good compliance is essential for successful medical treatment. Compliance can be evaluated using tablet counting, electronic monitoring systems and/or addition of a marker substance. In this study we evaluated the performance of low dose $(30 \mathrm{mg})$ bromide as a marker for distinguishing between $50 \%$ and $100 \%$ compliance in a group of healthy, well motivated volunteers.
Bromide was given in three different daily dosages (15, 24 and $30 \mathrm{mg}$ ) to three groups of eight healthy volunteers for 20 weeks to simulate compliance of 50, 80 and 100\%. Every 2 weeks compliance was evaluated using tablet counting and electronic monitoring, and a blood sample was taken for measuring serum bromide concentration using anion-exchange h.p.l.c. method. The mean increase in bromide in the $24 \mathrm{mg}$ day $^{-1}$ group was used as cut-off level to categorise subjects in 'good' or 'poor' compliance. Volunteers were characterised as having 'good' compliance if the increase in serum concentration was above the cutoff level in at least 3 of 4 visits at 8, 12, 16 and 20 weeks.

Results are shown in Table 1.

Serum bromide levels can reliably exclude subjects with $50 \%$ drug compliance. In contrast to tablet counting and electronic monitoring, use of a marker measures actual drug intake more reliably. Use of low dose bromide may therefore be a useful additional tool in the evaluation of compliance in individual patients.

\section{Table 1}

\begin{tabular}{|c|c|c|c|}
\hline & $15 m g d a y^{-1}$ & $\begin{array}{c}\text { Bromide } \\
24 \mathrm{mg} \mathrm{day}^{-1}\end{array}$ & $30 \mathrm{mg} \mathrm{day}^{-1}$ \\
\hline Compliance (tablet counting) & $100 \%$ & $98.8 \%$ & $99.9 \%$ \\
\hline Compliance (electronic monitoring) & $99.9 \%$ & $98.8 \%$ & $98.9 \%$ \\
\hline Steady state bromide serum concentration (mean \pm s.d., $\operatorname{mmol}^{-1}$ ) & $0.084 \pm 0.019$ & $0.14 \pm 0.03^{\mathrm{a}}$ & $0.19 \pm 0.06^{\mathrm{a}, \mathrm{b}}$ \\
\hline Good/poor compliance & $0 / 8$ & $3 / 5$ & $7 / 1$ \\
\hline
\end{tabular}

${ }^{\mathrm{a}} \mathrm{P}<0.01$ vs $15 \mathrm{mg}$ day ${ }^{-1},{ }^{\mathrm{b}} \mathrm{P}<0.05$ vs $24 \mathrm{mg}$ day $^{-1}$ (Mann-Whitney U test)

\section{Effectiveness of pharmacological treatment of hypertension in the reduction of the incidence of stroke in the general population}

\author{
O. H. KLUNGEL ${ }^{1,2,3}$, B. H. Ch. STRICKER ${ }^{2}$, M. B. B. \\ BRETELER $^{2}$, J. C. SEIDELL ${ }^{3}$, B. M. PSATY ${ }^{4} \&$ A. DE BOER ${ }^{1}$ \\ ${ }^{1}$ Department of Pharmacoepidemiology and Pharmacotherapy, \\ Utrecht University, Utrecht, ${ }^{2}$ Department of Epidemiology and \\ Biostatistics, Erasmus University Medical School, Rotterdam, \\ ${ }^{3}$ Department of Chronic Diseases and Environmental
}

Epidemiology, National Institute of Public Health and the Environment, Bilthoven, The Netherlands and ${ }^{4}$ Cardiovascular Health Research Unit, University of Washington, Seattle, USA

Some observational studies have not confirmed the beneficial effects of antihypertensive drug treatment on the incidence of stroke and coronary heart disease as demonstrated in randomized controlled clinical trials (RCTs). This contradiction is probably due to the biased comparison in most observational studies between treated hypertensive patients and prognostically different reference groups such as normo- 
tensives or untreated hypertensives regardless of their severity of hypertension and coexistence of other cardiovascular risk factors.

The aim of this study was to assess the effect of the pharmacologic treatment of hypertension under everyday circumstances on the incidence of stroke.

Approximately 45000 men and women aged $\geq 20$ years were examined in two population-based studies in the Netherlands. A cohort of 2616 hypertensive subjects who were either treated pharmacologically for hypertension $(n=$ 1318) or untreated hypertensives who were 'candidates' for pharmacologic treatment on the basis of the severity of their hypertension and the presence of other cardiovascular risk factors $(n=983)$ was followed up for a mean duration of 4.6 years and follow-up was complete for 2369 (91\%) subjects.
In this observational study, compared with untreated hypertensive subjects who were 'candidates' for pharmacologic treatment, subjects who were treated pharmacologically for hypertension had, after adjustment for differences in prognostic factors, a 39\% [95\% confidence interval (CI): 3-61\%] reduced risk of stroke. About 46 [95\% CI: 29-599] hypertensive patients need to be treated pharmacologically for 5 years to prevent one stroke in the general Dutch population.

When a prognostically comparable reference group is used, the pharmacological treatment of hypertension under everyday circumstances appears to be effective in the reduction of the incidence of stroke. The relative risk reduction that we found was similar to those published on the basis of results from RCTs.

\section{Bioavailability of oral hydroxocobalamin}

P-H. M. VAN DER KUY, F. W. H. M. MERKUS ${ }^{1}$, F. G. M. RUSSEL $^{2}$, J. J. H. M. LOHMAN ${ }^{3} \&$ P. M. HOOYMANS ${ }^{3}$

Department of Clinical Pharmacy, Laurentius Hospital, Roermond, ${ }^{1}$ Merkintech, Grootreesdijk 26, 2460 Kasterlee, Belgium, ${ }^{2}$ Department of Pharmacology and Toxicology, University of Nijmegen and ${ }^{3}$ Department of Clinical Pharmacy and Toxicology, Maasland Hospital, Sittard, The Netherlands

The use of oral vitamin $\mathrm{B}_{12}$ has been advocated for the treatment of pernicious anaemia [1]. A trial in the US carried out with daily $2 \mathrm{mg}$ cyanocobalamin (2 tablets of $1 \mathrm{mg}$ during breakfast) concluded that oral cobalamin was as effective after 4 months as $1 \mathrm{mg}$ of intramuscular treatment on a monthly basis [2]. However, no oral cobalamin preparation with a proven bioavailability is on the market and to our knowledge no pharmacokinetic comparison between oral (p.o.) and intramuscular (i.m.) administration has been published. Since hydroxocobalamin $\left(\mathrm{OHB}_{12}\right)$ is the drug of choice, we performed a cross-over randomized open study in six healthy volunteers (mean \pm s.d.: $38 \pm 12$ years) to compare the absorption of p.o. and i.m. $\mathrm{OHB}_{12}$.

Blood samples were taken immediately before dosing and at regular intervals up to $168 \mathrm{~h}$. The preparations administered were: i.m.: $1 \mathrm{mg} \mathrm{OHB}_{12}$ as Hydrocobamin ${ }^{\circledR}$ (Byk) and p.o.: $10 \mathrm{mg} \mathrm{OHB}_{12}$ in an aqueous solution with $200 \mathrm{ml}$ water after a light breakfast.

Pharmacokinetic parameters were calculated, using noncompartmental methods, after subtraction of the baseline cobalamin values $(t=0)$ from the values measured. A summary of the results is presented in Table 1 . The baseline $\mathrm{OHB}_{12^{-}}$ levels were comparable between the two groups (mean \pm s.d. in $\mathrm{nmol}^{-1}$ : $\quad$ p.o.: $\quad 0.42 \pm 0.20$; $\quad$ i.m.: $\left.\quad 0.34 \pm 0.09\right)$. AUC $(0,168 \mathrm{~h})$ after p.o. administration was not different from 0 (Wilcoxon signed rank test, $P=0.16$ ). The p.o. bioavail-

Table 1

\begin{tabular}{|c|c|c|c|c|}
\hline \multirow{2}{*}{$\begin{array}{l}\text { Pharmacokinetic } \\
\text { parameters }\end{array}$} & \multicolumn{2}{|c|}{$\operatorname{AUC}(0,168 h)\left(n m o l l^{-1} h\right)$} & \multicolumn{2}{|c|}{$\mathrm{C}_{\max }\left(\right.$ nmol l $\left.l^{-1}\right)$} \\
\hline & $1 \mathrm{mg}$ i.m. & $10 \mathrm{mg}$ p.o. & $1 \mathrm{mg}$ i.m. & $10 \mathrm{mg}$ p.o. \\
\hline Subject 1 & 964 & 12.5 & 21.4 & 0.27 \\
\hline 2 & 772 & 13.5 & 22.5 & 0.39 \\
\hline 3 & 900 & -7.6 & 24.7 & 0.06 \\
\hline 4 & 897 & 19.3 & 20.2 & 0.15 \\
\hline 5 & 1124 & -7.7 & 35.5 & 0.07 \\
\hline 6 & 842 & 3.6 & 28.7 & 0.17 \\
\hline Mean \pm s.d. & $920 \pm 120$ & $6 \pm 11$ & $26 \pm 6$ & $0.18 \pm 0.13$ \\
\hline $\begin{array}{l}\text { Dose corrected } \\
\text { ratio (i.m./p.o.) }\end{array}$ & \multicolumn{2}{|c|}{1530} & \multicolumn{2}{|c|}{1420} \\
\hline
\end{tabular}


ability calculated relative to the i.m. route is $0.07 \pm 0.13 \%$. No adverse reactions were reported. Despite the massive amount of $\mathrm{OHB}_{12}$ that was administered p.o. in this study, it can be concluded that the oral absorption of $\mathrm{OHB}_{12}$ is negligible. From this study it can be concluded that oral administration of hydroxocobalamin is not justified in patients in need of an adequate treatment in cobalamin deficiency.

1 Elia M. Lancet 1998; 352: 1721.

2 Kuzminski AM, et al. Blood 1998; 92: 1191.

\section{Angiotensin II sensitivity is asociated with the angiotensin II type 1 receptor $A^{1166} \mathrm{C}$ polymorphism in essential hypertensive patients}

W. SPIERING ${ }^{1}$, A. A. KROON ${ }^{1}$, M. J. M. J. FUSS-LEJEUNE ${ }^{1}$, M. J. A. P. DAEMEN ${ }^{2} \&$ P. W. DELEEUW ${ }^{1}$

Department of ${ }^{1}$ Internal Medicine and ${ }^{2}$ Pathology, Cardiovascular Research Institute Maastricht (CARIM), Maastricht University, Maastricht, The Netherlands

Several investigations have shown heterogeneity in the functional responses to angiotensin II (AngII) in patients with essential hypertension. The present study was initiated to evaluate whether the $\mathrm{A}^{1166} \mathrm{C}$ polymorphism of the AngII type I receptor (ATIR) gene contributes to this variability in AngII responses.

After 7 days high sodium diet $\left(220 \mathrm{mmol} \mathrm{Na}^{+}\right.$/day $)$we measured in 42 essential hypertensive patients blood pressure, heart rate (HR), effective renal plasma flow (ERPF), glomerular filtration rate (GFR), active plasma renin concentration (APRC), aldosterone, and atrial natriuretic peptide (ANP) before and during AngII infusion (increasing doses of $0.3,1.0$ and $3.0 \mathrm{ng} \mathrm{kg} \mathrm{min}^{-1}$ ). Calculated variables were filtration fraction $(\mathrm{FF})$ and renal vascular resistance (RVR). Patients in the three genotype groups (AA: $n=14$; AC: $n=17$; CC: $n=11$ ) were matched for sex, age, and body mass index.

At baseline, CC paients had decreased GFR $(P=0.06)$ and aldosterone $(P<0.05)$, and increased ANP $(P<0.05)$ as compared to AA patients. Moreover, responses of ERPE, GFR and RVR to the lowest concentration of AngII

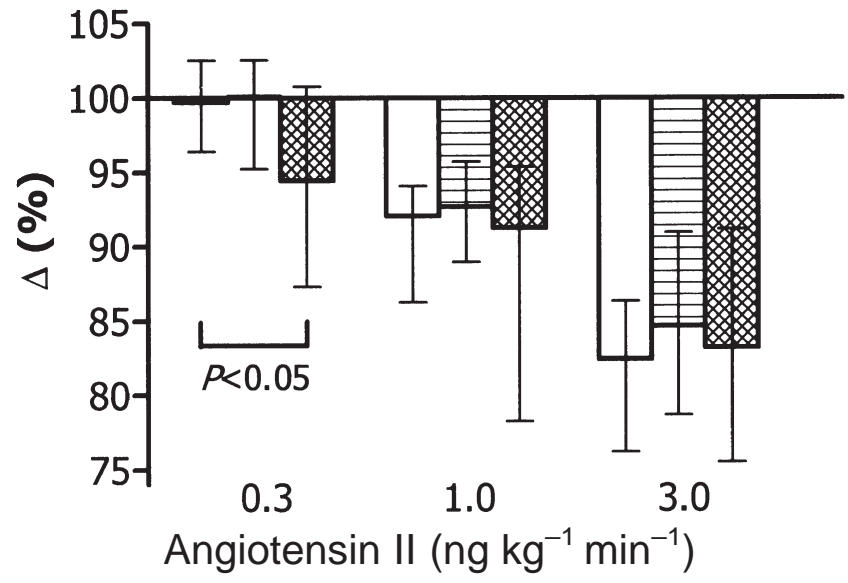

Figure 1 Responses of effective renal plasma flow to increasing doses of continuously infused AngII (median with interquartile ranges). $\square \mathrm{AA}$; $\boxminus \mathrm{AC}$; $\otimes \mathrm{CC}$.

$\left(0.3 \mathrm{ng} \mathrm{kg}^{-1} \mathrm{~min}^{-1}\right)$ were more pronounced in CC patients compared to AA patients (ERPF/GFR: $P<0.05$; RVR: $P=0.07)$, whereas maximal responses were all comparable between the groups. Heart rate was decreased at all levels of AngII infusion in CC patients, while it did not change in AA or AC patients. There were no differences in responses of APRC, aldosterone, and ANP to AngII between the three groups.

From these data we conclude that the $\mathrm{C}$ allele of the ATIR $A{ }^{1166} \mathrm{C}$ polymorphism is associated with increased sensitivity, but not reactivity to AngII. An augmented response to AngII may well be responsible for the increased incidence of cardiovascular abnormalities found in patients with 1 or $2 \mathrm{C}$ alleles. 